\title{
Hooked on Exercise: The Relationship between Exercise Addiction and Healthy Adherence in Collegiate Student-Athletes
}

\author{
Ksenia Berestetska ${ }^{1, *}$, Michael Sachs ${ }^{2}$ \\ Department of Kinesiology, Temple University, Philadelphia, USA \\ *Corresponding author: tug82764@temple.edu
}

Received September 17, 2018; Revised November 04, 2018; Accepted November 15, 2018

\begin{abstract}
Introduction: Exercise addiction is a prevalent issue among NCAA student-athletes that is often undiagnosed. The effects of excessive exercise involvement include but are not limited to lack of recovery time, acquisition of overuse injuries, and development of eating disorders. In addition, exercise addiction can result in low athletic and academic performances, subsequent depression, and resistance to seek professional assistance. The study findings may aid athletic administration and coaching staff in developing appropriate training methods that would facilitate student-athletes' healthy adherence to physical activity. Purpose: The purpose of the current study was to explore: a) the levels of Division I student-athletes’ physiological and psychological dependence on physical activity (exercise addiction); b) the frequency and duration of student-athletes' voluntary physical activity, in addition to the NCAA required training time; c) the motivational factors behind student-athletes' voluntary physical activity, and d) the relationship between student-athletes' exercise dependence and their weekly hours of voluntary physical activity. Methods: In total, 106 NCAA Division I collegiate athletes completed the Exercise Dependence Scale (EDS-21) and reported the duration and frequency of physical activity performed in addition to the NCAA required training. Participants also indicated the motivating forces behind their voluntary physical activity. Multiple linear regression and ANOVA tests were conducted to establish statistical significance for the relationships of interest. Results: Findings indicated, out of 106 student-athletes, $14.2 \%$ of athletes were identified as exercise dependent, while $62.3 \%$ of athletes demonstrated withdrawal symptoms. Exercise dependent student-athletes engaged in up to 6 hours of weekly physical activity in addition to the required 20-hour physical training $(M=4.27, S D=0.26)$. On the NCAA required day off, 63 student-athletes (59.43\%) engaged in up to 2 hours of physical activity $(M=1.34$, $S D=0.13$ ). Improving athletic performance was the main motivation behind athletes' voluntary physical activity. Further, the results of multiple linear regression and ANOVA revealed a strong positive relationship between student-athletes' exercise dependence and their weekly hours of voluntary physical activity $(F(1,104)=181.139$, $p<0.001, R=0.797)$. Thus, exercise dependent student-athletes engaged in much higher amounts of voluntary physical activity than symptomatic and asymptomatic student-athletes (Mean differences $=1.145$ and 3.267 hours, respectively). Discussion: Athletic administration and coaching staff can shape athletes' perceptions of healthy exercise habits and facilitate long-term healthy adherence to physical activity. Future research can examine the effectiveness of educational programs for exercise addiction prevention on student-athletes' abilities to detect maladaptive exercise habits.
\end{abstract}

Keywords: exercise addiction, exercise dependence, exercise adherence, exercise commitment

Cite This Article: Ksenia Berestetska, and Michael Sachs, "Hooked on Exercise: The Relationship between Exercise Addiction and Healthy Adherence in Collegiate Student-Athletes." Journal of Physical Activity Research, vol. 3, no. 2 (2018): 102-108. doi: 10.12691/jpar-3-2-7.

\section{Introduction}

The well-being of the National Collegiate Athletic Association (NCAA) student-athletes has been a central focus for many sport psychology experts [1,2,3]. In particular, scholars have examined the dimensions that influence student-athletes' motivation to continue exercise and sport participation $[4,5,6,7]$. One of the aspects that plays a key role in student-athletes' desire to continue collegiate as well as post-collegiate exercise/sport participation is the amount of required physical training $[8,9]$. Because in-season student-athletes participate in 20 hours of weekly on and off the court/field physical workload, in addition to the time spent in competition [10], they encounter multiple effects caused by regular intensive exercise participation [11]. The most prevalent consequences of physical overload among collegiate athletes are lack of recovery time, acquisition of overuse 
injuries, burnout and, consequently, decreased desire to further participate in exercise and sport $[9,12,13,15]$.

In addition to the physiological and psychological issues caused by physical overtraining, student-athletes face challenges of balancing academic and athletic workloads $[2,14]$. The NCAA requires student-athletes to have a full-time academic enrollment, in addition to the 20 hours of required physical training as well as frequent traveling for away meets/games [10]. These factors potentially overwhelm student-athletes and negatively impact their motivation to adhere to long-term physical activity [15].

On the contrary, physical overtraining and high demands to produce successful results can also lead to the development of exercise addiction [16]. Exercise addiction (i.e., exercise dependence) is characterized by excessive involvement in strenuous physical activity $[17,18]$. An athlete who exercises obsessively is driven by an irresistible impulse to continue physical activity despite physical or psychological problems, such as injury, fatigue, illness. An athlete may also feel obligated to engage in excessive exercise to avoid withdrawal symptoms, such as feelings of guilt, anxiety, restlessness, and frustration, which would manifest in case of discontinued exercise participation $[17,18]$. The key factor in determining whether an exercise habit becomes an addiction is when it destroys an individual's ability to cope with or experience feelings of excitement, joy, and pleasure from engaging in leisure and social life activities [19]. An exercise addicted athlete is unable to control their exercise habits to the extent when workouts hurt an athlete's daily functioning (due to decreased physical health, decreased life satisfaction, poor performance, and mental exhaustion) and interfere with other social obligations $[19,20]$. Currently, there are no mandatory screening tests or educational programs for exercise addiction prevention in NCAA institutions, which results in many exercise addiction occurrences remaining undetected.

Considering the discussed factors which facilitate or impede exercise participation, there is a need to explore the effects of required sport participation on student-athletes' voluntary exercise involvement. To fill this gap, our study examined the frequency and duration of student-athletes' voluntary physical activity, identified exercise addiction occurrences, and explored the motivations behind studentathletes' exercise addiction. Thus, this study investigated the following areas: a) the levels of Division I studentathletes physiological and psychological dependence on physical activity (exercise addiction); b) the frequency and duration of student-athletes' voluntary physical activity, beyond the NCAA required training time; c) the motivational factors behind student-athletes' voluntary physical activity, and d) the relationship between student-athletes' exercise addiction and their weekly hours of voluntary physical activity.

The goal of the study is to determine the ramifications of physical overtraining encountered by collegiate studentathletes on their exercise addiction and long-term exercise commitment. The potential findings of the study may aid athletic administration and coaching staff in developing appropriate training methods that would facilitate long-term healthy adherence to physical activity. Another goal of the study is to help student-athletes shape healthy perceptions of physical activity in order to prevent the development of exercise addiction.

\section{Methods}

\subsection{Study Procedures and Participants}

Prior to data collection, this study was approved by the Institutional Review Board at Temple University. The method used in the data collection process was the online survey distribution. First, the survey link accompanied by the study information was distributed via e-mail on April $11^{\text {th }}, 2018$, to Temple University head and assistant coaches. Then, coaches were asked to forward the survey information to their student-athletes. Participants were Division I Temple University student-athletes. Eligibility criteria included: reaching a minimum of 18 years old, competing in varsity sports, and being on the official team roster. Participants were informed about the confidentiality of their responses and could take as much time as needed to complete the survey. Overall, three rounds of e-mails were sent to coaches on April $11^{\text {th }}$, May $2^{\text {nd }}$, and August $29^{\text {th }}, 2018$. Data collection ended on September $27^{\text {th }}, 2018$. The anonymous online survey, administered through the Qualtrics Survey Software, captured 106 fully completed responses.

\subsection{Measures and Instruments}

The overall measures collected in the study were the levels of physiological and psychological dependence on exercise (exercise addiction), the amount of weekly physical activity, and the motivations behind voluntary physical activity in addition to the required training time.

\subsubsection{Exercise Addiction/Dependence}

To assess exercise addiction (i.e., exercise dependence) symptoms among student-athletes [21], the Exercise Dependence Scale-21 (EDS-21) was utilized. The 21-item EDS comprised the following seven criteria: withdrawal effects (items 1, 8, 15), continuance (items 2, 9, 16), tolerance (items 3, 10, 17), lack of control (items 4, 11, 18), reduction in other activities (items $5,12,19)$, time (items 6, 13, 20), and intention effects (7, 14, 21). Each item was measured by means of a 7-point Likert scale, where a rating of 1 represented "strongly disagree," while a rating of 7 corresponded to "strongly agree" [21].

The manifestations of all seven components of the EDS-21 are explained further. Withdrawal effects from exercise dependence manifest through either the characteristic withdrawal symptoms for exercise (e.g., nervousness, fatigue, anxiety) or through the same amount of exercise in which an individual engages to relieve or avoid withdrawal symptoms [22]. Continuance manifests through continuous engagement in physical activity despite an individual's acknowledgement of a persistent or recurring physical problem, most likely caused or exacerbated by the exercise (e.g., exercising despite injury). Tolerance shows an individual's need for increased amount of exercise to achieve the desired effect, otherwise, a diminished effect could occur if the same amount of exercise is performed. Lack of control represents a persistent desire or unsuccessful attempt to reduce or control exercise, while the time factor indicates a prolonged participation in physical activity solely for obtaining exercise (e.g., physical activity vacation). Intention effects occur when an individual 
frequently exercises in larger amounts or longer than intended originally. Finally, reduction in other activities manifests through an individual's reduced engagement or disengagement in social, occupational, or recreational activities solely for exercise [22].

\subsubsection{Physical Activity Amounts}

To explore athletes' exercise engagement in addition to the NCAA required training time, we asked the participants the following questions: "How many hours do you engage in physical activity weekly on your own?" and "How many hours do you spend on physical activity on the NCAA required day off?" We also asked student-athletes what types of exercise(s) they perform voluntarily (e.g., running, swimming, cycling, lifting) to investigate whether these athletes play their sport in addition to the required training, perform specific sport-related exercises to aid their athletic performance, or engage in additional exercise for their own pleasure.

\subsubsection{Motivations behind Excessive Exercise}

We asked the participants about the motivating forces behind their excessive physical activity (i.e., "I exercise on my own because my coach encourages me to do so," "I exercise on my own because I like to exercise," and "I exercise on my own because I want to improve my performance”).

\subsubsection{Demographic Measures}

The participants completed a 5-item demographic questionnaire to assess their age, gender, year in school, years of overall experience participating in sport, and scholarship status.

\subsection{Statistical Analysis}

The SPSS Statistics Software (version 24.0) was used for data analysis. First, descriptive statistics were calculated for each demographic variable. Second, alpha coefficients were computed for each subscale of the Exercise Dependence Scale-21 (EDS-21) to determine the internal consistency and reliability of the data. The recommended Cronbach's alpha level used for ensuring high internal consistency of the items was .80 [23]. The overall alpha level for the EDS-21 instrument was greater than the .80 value $(\alpha$ $=.96$ ). Furthermore, the alpha levels for each subscale of the EDS-21 exceeded the recommended .80 value. Due to high statistical reliability, all subscales of the EDS-21 were included in the data analysis (see Table 1).

Table 1. Internal consistency estimates for subscales

\begin{tabular}{lcccc}
\hline $\begin{array}{l}\text { Subscale of the } \\
\text { EDS-21 }\end{array}$ & $\begin{array}{c}\text { Number } \\
\text { of items }\end{array}$ & $M$ & $S D$ & Cronbach's $\alpha$ \\
\hline Withdrawal Effects & 3 & 10.11 & 4.12 & .90 \\
Continuance & 3 & 9.05 & 4.09 & .89 \\
Tolerance & 3 & 12.42 & 3.37 & .86 \\
Lack of Control & 3 & 8.18 & 3.75 & .86 \\
Reduction in Other & 3 & 7.62 & 3.34 & .84 \\
Activities & 3 & 10.63 & 3.52 & .84 \\
Time & 3 & 8.47 & 3.76 & .95 \\
Intention Effects & 21 & 66.49 & 20.94 & .96 \\
Overall EDS-21 & & & \\
Scale Statistics & & & &
\end{tabular}

*Total mean, standard deviation, and reliability scores for the Exercise Dependence Scale- 21.

\section{Results}

\subsection{Descriptive Statistics}

A total of 106 participants (61 males and 45 females) completed an anonymous online survey. The ages of participants ranged from 18 to 24 years $(M=19.75$; $M d n$ $=20 ; S D=1.30)$. In regards to student-athletes' school year, 28 freshmen (26.4\%), 29 sophomores (27.4\%), 25 juniors (23.6\%), 19 seniors (17.9\%), 1 super senior $(0.9 \%)$, and 4 graduate students $(3.8 \%)$ completed the questionnaire. Student-athletes competed in 16 sports with the most frequent responses from soccer ( $n=27 ; 25.5 \%$ ), cross country and track and field combined ( $n=17 ; 16.1 \%)$, tennis ( $n=15 ; 14.2 \%)$, crew $(n=12 ; 11.3 \%)$, and gymnastics ( $n=9 ; 8.5 \%)$. In addition, participants' overall experience of sport participation ranged from 1 to 19 years $(M=10.44$; $M d n=11 ; S D=4.99$ ).

The student-athletes were grouped by scholarship status (i.e., walk-on, partial, and full scholarship). Walk-ons were students without funding from the university. Partial scholarship status reflected at least some form of funding from the school (full tuition and partial room and board). Full scholarship status included full tuition, fees remission, books, and room and board, all of which were sponsored by the school. Of the respondents, $38.7 \%$ had a full scholarship ( $n=41)$, 31.1\% had a partial scholarship $(n=33)$, and $30.2 \%$ were walk-ons $(n=32)$.

\subsection{Exercise Addiction and Weekly Physical Activity}

EDS-21 scores were calculated using the EDS-21 Statistical Package for the Social Sciences (SPSS) syntax file provided in the EDS-21 Manual [24]. This scoring procedure is computer based, which produces immediate and accurate scoring. According to the syntax file [24], participants can be classified as exercise dependent, nondependent-symptomatic, or nondependent-asymptomatic. Athletes who scored 5 or more on the 7-point Likert scale on at least 3 out of 7 criteria of the EDS-21 instrument (see 2.2.1) were classified as exercise dependent. Athletes who scored in the 3 to 4 range on the 7-point Likert scale on at least 3 criteria were classified as nondependent-symptomatic. These individuals may theoretically be considered at-risk for exercise dependence. Finally, individuals who scored 1 or 2 on the 7 -point Likert scale on at least 3 criteria were classified as nondependent-asymptomatic.

Out of the total number of participants $(N=106), 15$ athletes $(14.2 \%)$ were identified as exercise dependent or at-risk for exercise dependence, 66 athletes (62.3\%) classified as nondependent-symptomatic, and 25 athletes (23.6\%) were nondependent-asymptomatic. Exercise dependent student-athletes participated in the following sports: soccer $(n=2)$, crew $(n=1)$, cross country and track and field $(n=2)$, football $(n=3)$, basketball $(n=2)$, volleyball $(n=1)$, and tennis $(n=3)$. In addition, 44 student-athletes $(41.51 \%)$ were classified as exercise dependent at least by one criterion of the EDS-21. Those 95 student-athletes who engaged in voluntary exercise reported they spent up to 6 hours on physical activity per week $(M=3.98, M d n=3.00, S D=0.24)$. On the NCAA required day off, 63 student-athletes (59.43\%) of the 106 
participants engaged in up to 2 hours of physical activity $(M=1.34, M d n=1.00, S D=0.13)$.

Further, to compare the duration of voluntary exercise participation among the three previously mentioned categories of exercise addiction (exercise dependent, nondependent-symptomatic, and nondependent-asymptomatic), exercise dependent athletes engaged in up to 6 hours of physical activity per week, in addition to the required training time. Exercise nondependent-symptomatic athletes reported up to 5 hours of voluntary physical activity per week, while nondependent-asymptomatic athletes engaged in up to 2 hours of physical activity weekly (see Table 2).

On the NCAA required day off, exercise dependent athletes engaged in up to 2 hours of physical activity $(M=1.07, M d n=1, S D=0.12)$, while nondependentsymptomatic and asymptomatic athletes still dedicated up to 1 hour to exercise $(M=0.62, M d n=0.50, S D=0.08$ for symptomatic; $M=0.40, M d n=0.34, S D=0.06$ for asymptomatic).

Table 2. Hours of voluntary physical activity per week

\begin{tabular}{lcccc}
\hline Category & Maximum & Mean & Median & SD \\
\hline Exercise Dependent & 6 hours & 4.27 & 4 & 0.26 \\
Symptomatic Nondependent & 5 hours & 3.12 & 3 & 0.14 \\
Asymptomatic Nondependent & 2 hours & 1.27 & 1 & 0.11 \\
\hline
\end{tabular}

Table 3. Multiple regression analysis results

\begin{tabular}{lllllll}
\hline $\mathrm{R}$ & $\mathrm{R}^{2}$ & Adjusted $\mathrm{R}^{2}$ & Std. Error & $\mathrm{F}$ & $\mathrm{df} 1, \mathrm{df} 2$ & Significance \\
\hline .797 & .635 & .632 & .795 & 181.139 & 1,104 & .000 \\
\hline
\end{tabular}

a. Independent variable: exercise dependence category, b. Dependent variable: weekly hours of voluntary physical activity.

Table 4. ANOVA Post Hoc test (multiple comparisons)

\begin{tabular}{|c|c|c|c|c|}
\hline $\begin{array}{c}\text { (I) Exercise } \\
\text { Dependence } \\
\text { Category }\end{array}$ & $\begin{array}{c}\text { (J) Exercise } \\
\text { Dependence } \\
\text { Category }\end{array}$ & $\begin{array}{c}\text { Mean } \\
\text { Difference } \\
(\mathrm{I}-\mathrm{J})\end{array}$ & $\begin{array}{l}\text { Std. } \\
\text { Error }\end{array}$ & Significance \\
\hline \multirow{2}{*}{$\begin{array}{c}\text { Exercise } \\
\text { Dependent }\end{array}$} & $\begin{array}{l}\text { Nondependent- } \\
\text { symptomatic }\end{array}$ & 1.14545 & .218 & .000 \\
\hline & $\begin{array}{l}\text { Nondependent- } \\
\text { asymptomatic }\end{array}$ & 3.26667 & .249 & .000 \\
\hline \multirow{2}{*}{$\begin{array}{l}\text { Nondependent- } \\
\text { symptomatic }\end{array}$} & $\begin{array}{c}\text { Exercise } \\
\text { dependent }\end{array}$ & -1.14545 & .218 & .000 \\
\hline & $\begin{array}{l}\text { Nondependent- } \\
\text { asymptomatic }\end{array}$ & 2.12121 & .179 & .000 \\
\hline
\end{tabular}

*Dependent variable: weekly hours of voluntary physical activity.

Further, multiple linear regression and ANOVA tests were conducted to examine the link between student-athletes' exercise dependence and their weekly hours of voluntary physical activity (see Table 3). Multiple linear regression revealed a strong relationship between student-athletes' exercise dependence and the weekly hours of voluntary physical activity $(F(1,104)=181.139, p<0.001)$. The Pearson correlation coefficient [25] demonstrated a positive relationship between exercise dependence and weekly hours of voluntary physical activity in athletes $(R=0.797)$. As a result, higher exercise dependence levels were associated with increased amounts of voluntary physical activity $\left(R^{2}=0.635\right)$. In addition, ANOVA results showed statistically significant differences between the three categories of exercise dependence and the weekly hours of voluntary physical activity $(F(1,104)=181.139$, $p<0.001)$. The Post Hoc test determined that exercise dependent student-athletes engaged in higher amounts of weekly voluntary physical activity than nondependent-symptomatic (Mean difference $=1.145$ hours), and nondependent-asymptomatic student-athletes (Mean difference $=3.267$ hours, see Table 4).

\subsection{Motivations for Physical Activity}

The results revealed that exercising to improve athletic performance was the primary motivation behind athletes' excessive exercise participation (56.25\% of all responses for "strongly agree," frequency =63). The second leading motivation for additional exercise was exercising for one's own pleasure (33.04\% of all responses for "strongly agree," frequency $=37$ ), while the least frequent reason was exercising due to coach's encouragement $(10.71 \%$ of all responses for "strongly agree," frequency $=12$ ).

Further, participants listed up to three exercise types in which they engaged voluntarily. While athletes engaged in various types of physical activity during their leisure time, only 8 out of 95 athletes $(8.42 \%)$ participated in sportrelated exercise. Overall, $93.2 \%$ of the total weekly physical activity for all participants (348.1 out of 373.5 hours) was not related to athletes' sports. The five most frequent exercise types among 95 athletes who exercised voluntarily were: running or jogging (36.08\%, frequency $=35)$, weight lifting $(31.96 \%$, frequency $=31)$, abdominal exercise $(16.49 \%$, frequency $=16)$, swimming $(9.28 \%$, frequency $=9)$, and cycling $(7.22 \%$, frequency $=7)$.

\section{Discussion}

\subsection{Exercise Addiction}

The fact that $89.62 \%$ of student-athletes in our sample engaged in physical activity in addition to the required 20hour weekly training indicates that a large population of student-athletes view leisure exercise as an integral part of their daily activities. Further, $14.2 \%$ of all athletes in our sample were identified as at-risk for exercise dependence, $62.3 \%$ were classified as nondependent-symptomatic, and $23.6 \%$ were nondependent-asymptomatic. In addition, $41.51 \%$ of athletes were classified as exercise dependent on at least one criterion of the EDS-21.

In a similar study on social forces and psychological processes that led to exercise addiction among elite Australian athletes, out of 198 participants, 69 athletes (34.84\%) scored high enough to be classified as exercise dependent, while 182 athletes (91.92\%) were exercise dependent on at least one out of seven criteria of the Diagnostic and Statistical Manual - Fourth Edition (DSM - IV) for substance addiction [16]. Thus, elite Australian athletes exhibited a higher frequency of exercise addiction cases compared to Division I student-athletes in our study. This difference could be explained by collegiate athletes' full-time involvement in academics, which could significantly decrease the frequency and duration of voluntary exercise.

Other studies on the prevalence of exercise addiction among athletic populations found 52\% out of 203 triathletes [26] 
and over $50 \%$ out of 184 competitive runners [27] classified at-risk for exercise dependence. Significantly higher levels of exercise addiction among elite athletes compared to student-athletes in our study could also be explained by the competitive nature of professional sports, in which elite athletes engage on a full-time basis without additional occupational obligations. On the contrary, the median time spent by student-athletes on physical training and competition ranges from 32 hours per week in-season up to 42 hours per week (football), in addition to frequent traveling for away games on weekends and a full-time academic requirement [28]. These obligations, in turn, could impede student-athletes' voluntary exercise participation.

In regards to motivations for voluntary physical activity, student-athletes in our study reported that improving one's athletic performance was the main motivational force behind excessive physical activity. Athletes also engaged in voluntary exercise for the fulfillment of the coach's encouragement to exercise additionally. Similar studies on motivational forces behind excessive physical activity also found that elite athletes experienced pressure from social forces, particularly coaches and teammates, to engage in additional physical training [16,29]. Thus, athletes could develop exercise addiction due to the pressure generated by coaches and teammates to train more intensely, enhance athletic performance, and demonstrate successful results in sport.

\subsection{Practical Implications}

By presenting our findings and corroborating them with previously conducted studies on the prevalence of exercise addiction across athletic populations [16,26,27], we can draw useful practical implications for Division I University athletes, coaches, and administrative staff. The main goal of our study was to determine the frequency of exercise addiction cases among Division I student-athletes in relation to its impact on athletes' voluntary exercise commitment. By revealing the motivations behind student-athletes' exercise addiction, we intended to help coaches develop appropriate training methods that would optimize student-athletes' performance and overall health, shape athletes' perceptions of healthy exercise habits, and facilitate an increased desire for long-term exercise adherence during and after collegiate sport participation.

By examining our study results, we can conclude that the exercise addiction condition may affect a significant number of Division I student-athletes. More importantly, exercise addiction could further lead to the development of various psychological disorders [16,26]. Specifically, athletes engaging in excessive exercise behaviors are at-risk for unhealthy eating and resulting eating disorders $[16,30,31]$. It is also important to consider that at-risk for exercise dependence athletes experience lower social support than asymptomatic exercise non-dependent athletes [16,30,31]. Consequently, exercise dependent student-athletes may potentially acquire maladaptive approaches of dealing with the pressure to produce outcomes created by coaches, teammates, and academic requirements. Creating professional assistance services and encouraging exercise dependent student-athletes to seek guidance from Athletics Department/University mental health professionals could be a way to compensate for low social support. In addition, there is a need to introduce athletes to the concept of exercise addiction and educate them on the physiological and psychological effects of overtraining.

Furthermore, coaches could play a pivotal role in preventing maladaptive exercise behaviors of their athletes. By effectively communicating with athletes and educating them about the concept of exercise addiction during individual and team meetings, coaches could help athletes identify whether they suffer from withdrawal symptoms of exercise addiction, such as irritability, fatigue, insomnia, and depression [32]. By learning from coaches how to assess personal levels of exercise addiction, athletes could independently determine when their voluntary exercise habits become detrimental to their health.

Finally, coaches could facilitate their athletes' further exercise participation by creating a positive training environment on and off the field/court. As noted in previous studies on the influence of coaching behaviors on Division I student-athletes' sport commitment [33,34], coaches could positively contribute to their athletes' long-term sport and exercise adherence. Specifically, coaches who provide their athletes with sufficient social support, positive feedback, and situational considerations could significantly increase their athletes' levels of longterm exercise and sport commitment [33,34,35].

Drawing conclusions from our study, coaches can assist symptomatic or exercise dependent student-athletes by creating a positive training environment. For instance, coaches need to express concerns for the physical and mental health of their players as well as build interpersonal relationships with them to be aware of any issues that their athletes might experience. In addition, coaches need to minimize the levels of social pressure by developing an individual approach to every athlete, cooperating with an athlete on setting specific goals, considering the athlete's time and effort, and avoiding punishment in the form of exercise. Lastly, coaches need to compliment players for their performance efforts regardless of the outcome and express appreciation for their individual contributions to the team. Through these methods coaches could not only prevent the development of exercise addiction, but also increase athletes' enjoyment from sport participation and motivate them to engage in long-term healthy physical activity.

\subsection{Limitations and Future Directions}

The current study had several limitations. First, only one Division I University student-athletes were recruited to participate in this study. Thus, the prevalence and psychological factors associated with negative exercise addiction could vary for athletes from other Division I universities or colleges/universities at other NCAA Division levels. Second, the instances of exercise addiction may not have been representative of all sports. Samples of at least $30 \%$ of student-athletes on given teams were obtained only in men's soccer, men's crew, tennis, gymnastics, cross country and track and field. However, few responses were collected in other sports, which could lead to nonresponse bias. We found sporadic occurrences of exercise addiction among football, soccer, tennis, basketball, volleyball, and crew athletes. Thus, no consistent patterns of exercise addiction were exhibited in all sports and 
genders. Nevertheless, this factor emphasizes the existence of negative exercise addiction across various sports. Therefore, larger samples of the same sports should be investigated in future studies to determine whether exercise addiction is prevalent in certain sports and genders.

Another limitation of our study is related to the context of collegiate athletics. Because student-athletes undergo at least 20 hours of weekly physical training, frequent traveling, and full-time academic commitments [10], requiring substantial physical and mental demands, desire to engage in voluntary exercise can be greatly hindered. In addition, athletes might lack an opportunity to adhere to leisure exercise due to time constraints. By considering these factors in future studies, researchers need to explore the reasons why student-athletes who are motivated to engage in additional physical activity choose not to do so (e.g., lack of time, physical exhaustion, mental burnout, etc.). By considering athletes' motivations and personal needs for additional physical exercise (e.g., to improve one's level of fitness, refine a certain sport-related skill, or perform a favorite exercise an athlete does not engage in during practice), coaches could potentially increase their athletes' enjoyment of the training process and positively contribute to their long-term healthy exercise adherence.

Furthermore, research needs to be conducted to examine the effectiveness of structured educational programs for exercise addiction on student-athletes' abilities to independently detect their maladaptive exercise habits. Currently, there are no educational programs and screening tools available for student-athletes aimed toward helping them identify exercise addiction symptoms. To fill this gap, there is a need to examine the effectiveness of an educational program for exercise addiction prevention on student-athletes' abilities to independently and accurately identify their maladaptive physical activity.

Finally, a longitudinal study needs to be conducted to examine the changes in student-athletes' levels of exercise addiction from their freshman to senior years, and beyond their college careers. This study would reveal whether exercise dependent student-athletes retain their compulsive behavior over years, indicating that their post-graduation exercise commitment is more likely to occur. On the contrary, exercise dependent athletes could withdraw from a formerly enjoyable physical activity due to physical overtraining and mental burnout that they acquired from athletic participation [9]. In addition, such a study would show whether symptomatic athletes tend to develop exercise addiction over the years and whether nondependent-asymptomatic athletes continue to adhere to healthy exercise habits after graduation. Based on the exhibited tendencies of exercise participation among student-athletes, researchers could develop strategies aimed to combat exercise addiction and facilitate long-term healthy exercise adherence.

\section{Acknowledgements}

The authors wish to thank Temple University student-athletes who participated in the study and Temple University coaching staff who helped in the process of data collection.

\section{Compliance with Ethical Standards}

The authors declare that they have no conflicts of interest. In conducting the study, the authors strictly adhered to the ethical standards of the institutional and/or national research committee and to the 1964 Helsinki declaration and its later amendments or comparable ethical standards.

\section{References}

[1] Kamusoko, S., \& Pemberton, C. (2011). Student-athlete wellbeing and higher education persistence. Journal of Issues in Intercollegiate Athletics, 4, 207-235.

[2] Miller, P., \& Gretchen, K. (2002). The athletic, academic, and social experiences of intercollegiate student-athletes. Journal of Sport Behavior, 25(4), 346-367.

[3] Jingzhen, Y., Peek-Asa, C., Corlette, J. D., Cheng, G., Foster, D., \& Albright, J. (2007). Prevalence and risk factors associated with symptoms of depression in competitive collegiate student athletes. Clinical Journal of Sport Medicine, 17(6), 481-487.

[4] Raymond, N. (2016). Examining motivation to participate in sport: A retrospective look at current and former athletes' motivation to participate in athletics. Theses and Dissertations (All). Paper 1398. Retrieved from https://knowledge.library.iup.edu/etd/1398.

[5] Tudor, M. (2014). Predicting Student Athletes' Motivation Towards Academics and Athletics (Doctoral Dissertation). Retrieved from https://etd.ohiolink.edu/

[6] Amorose, A., \& Horn, T. (2000). Intrinsic motivation: Relationships with collegiate athletes' gender, scholarship status, and perceptions of their coaches' behavior. Journal of Sport \& Exercise Psychology, 22, 63-84.

[7] Smith, R. (2000). A brief history of the national collegiate athletic association's role in regulating intercollegiate athletics. Marquette Sport Law Review, 11(1), 12-13.

[8] Metzler, J. (2002). Applying motivational principles to individual athletes. In J. M. Silva \& D. E. Stevens (Eds.), Psychological foundations of sport (pp. 80-106). Boston: Allyn and Bacon.

[9] Gould, D., \& Whitley, M.A. (2009). Sources and consequences of athletic burnout among college athletes. Journal of Intercollegiate Sport, 2(1), 16-30.

[10] National Collegiate Athletic Association. (2016a). NCAA Division I Manual. Overland Park, KS: NCAA.

[11] Fields, S., Collins, C., \& Comstock, R. (2007). Conflict on the court: Review of sport-related violence literature. Trauma, Violence, \& Abuse, 8(4), 359-369.

[12] Coakley, J. (2007). Sport in society: Issues and controversies (9th ed.). Boston, MA: McGraw-Hill.

[13] Dick, R.W. (1997). A comparison of injuries that occur during collegiate fall and spring football using the NCAA Injury Surveillance System. In: Hoerner, E.F., (Ed.), Safety in American Football. Philadelphia, PA: American Society for Testing and Materials.

[14] Maloney, M., \& McCormick, R. (1993). An examination of the role that intercollegiate athletic participation plays in academic achievement: Athletes' feats in the classroom. The Journal of Human Resources, 28(3), 555-570.

[15] Gustafsson, H., Kentta, G., Hassmen, P., \& Lindquist, C. (2007). Prevalence of burnout in competitive adolescent athletes. The Sport Psychologist, 21, 21-27.

[16] McNamara, J., \& McCabe, M. P. (2012). Striving for success or addiction? Exercise dependence among elite Australian athletes. Journal of Sports Sciences, 30(8), 755-766.

[17] Berczik, K., Szabó, A., Griffiths, M.D., Kurimay, T., Kun, B., Urbán, R., Demetrovics, S. (2012). Exercise addiction: Symptoms, diagnosis, epidemiology, and etiology. Substance Use \& Misuse, 47(4), 403-417.

[18] American Psychiatric Association. Diagnostic and statistical manual of mental disorders ( $4^{\text {th }}$ ed.). Washington, DC: The Association, 1994. 
[19] Peele, S. (1985). The Meaning of Addiction. Compulsive Experience and Its Interpretation. Lexington, KY: Lexington Books. pp. 1-26.

[20] Glasser, W. (1976). Positive addiction. New York, NY: Harper \& Row.

[21] Hausenblas, H. A., \& Symons Downs, D. (2002a). A review of exercise dependence. Psychology of Sport and Exercise, 3(2), 89-123.

[22] Hausenblas, H. A., \& Symons Downs, D. (2002b). How much is too much? The development and validation of the exercise dependence scale. Psychology and Health, 17(4), 387-404.

[23] George, D., \& Mallery, P. (2003). SPSS for Windows step by step: A simple guide and reference. 11.0 update (4th ed.). Boston: Allyn \& Bacon.

[24] Hausenblas, H. A., \& Symons Downs, D. (2001). The Exercise Dependence Scale manual. Unpublished test manual, University of Florida, Gainesville, FL.

[25] Spiegel, M. R. (1992). Theory and problems of probability and statistics (2nd ed.). New York, NY: McGraw-Hill.

[26] Blaydon, M. J., \& Linder, K. J. (2002). Eating disorders and exercise dependence in triathletes. Eating Disorders, 10(1), 49-60.

[27] Smith, D., Wright, C., \& Winrow, D. (2010). Exercise dependence and social physique anxiety in competitive and noncompetitive runners. International Journal of Sport and Exercise Psychology, 8(1), 61-69.

[28] National Collegiate Athletic Association. (2016, January). Results from the 2015 GOALS study of the student-athlete experience.
Research presented at the National Collegiate Athletic Association in San Antonio, TX.

[29] Beam, J.W. (2001). Preferred leadership of NCAA Division I and II intercollegiate student-athletes. UNF Theses and Dissertations. Retrieved from

https://digitalcommons.unf.edu/cgi/viewcontent.cgi?referer=https:/ /scholar.google.com/\&httpsredir=1\&article=1166\&context=etd.

[30] Carter, J.E., \& Rudd, N.A. (2006). Disordered eating assessment for college student-athletes. Women in Sport and Physical Activity Journal, 14(1), 62-71.

[31] Johnson, C., Crosby, R., Engel, S., Mitchell, J., Power, P., Wittrock, D., \& Wonderlich, S. (2004). Gender, ethnicity, selfesteem and disordered eating among college athletes. Eating Behaviors, 5(2), 147-156.

[32] Morris, M., Steinberg, H., Sykes, E. A., \& Salmon, P. (1990). Effects of temporary withdrawal from regular running. Journal of Psychosomatic Research, 34, 493-500.

[33] Price, M., \& Weiss, M. (2000). Relationships among coach burnout, coach behaviors, and athletes' psychological responses. The Sport Psychologist, 14, 391-409.

[34] Andrew, D.P.S., \& Kent, A. (2007). The impact of perceived leadership behaviors on satisfaction, commitment, and motivation: An expansion of the Multidimensional Model of Leadership. International Journal of Science Coaching, 1(1), 37-58.

[35] Hollembeak, J., \& Amorose, A.J. (2005). Perceived coaching behaviors and college athletes' intrinsic motivation: A tests of Self-Determination Theory. Journal of Applied Sport Psychology, 17(1), 20-36. 